\title{
A study on phenol migration by coupling the liquid membrane in the ionic liquid
}

\author{
Shibao $\mathrm{Lu}^{a, *}$, Liang Pei ${ }^{b}$ \\ a School of Public Administration, Zhejiang University of Finance and Economics, Hang Zhou 310018, China \\ ${ }^{\mathrm{b}}$ Key Laboratory of Water Cycle and Related Land Surface Processes, Institute of Geographic Sciences and Natural \\ Resources Research, Chinese Academy of Sciences, Beijing 100101, China
}

\section{A R T I C L E I N F O}

Article history:

Received 30 March 2016

Accepted 3 May 2016

Available online 29 May 2016

Keywords:

Ionic liquid

Synthesis

Liquid membrane separation

Phenol

Wastewater treatment

\begin{abstract}
A B S T R A C T
The environmental pollution of phenol is primarily taken as a result of wastewater discharged from some special chemical plants. It is the common pollutant to be controlled in industrial wastewater, and therefore, how to effectively minimize its environmental pollution by the phenolic pollutants treatment and recovery becomes an important subject. This paper aims to make a study on the support liquid membrane separation from phenolic wastewater in hydrated environment. The process of separation is conducted with hydrophobic ionic liquid 1-butyl-3-methylimidazole hexafluorophosphate [BMIM] $\mathrm{PF}_{6}$ prepared by the microwave synthesis method based on fundamental solvent extraction research and applied to the inner coupling liquid membrane system. as the purpose is to migrate phenol in the simulated wastewater and survey the temperature, stirring speed, feed liquid phase acidity, initial concentration and $\mathrm{NaOH}$ concentration in the stripping phase influence on the phenol migration to obtain the preferred condition for migration. The said condition is as follows: The temperature of $300 \mathrm{~K}$, the stirring speed ranging from 350 to $400 \mathrm{rpm}$, the feed liquid phase $\mathrm{pH}$ of 3.65 , and $\mathrm{NaOH}$ concentration of $0.8 \mathrm{~mol} / \mathrm{L}$ in the stripping phase. In the system, phenol is approximated to $100 \%$ in migration rate and the ionic liquid may be recycled for several times.
\end{abstract}

๑ 2016 Hydrogen Energy Publications LLC. Published by Elsevier Ltd. All rights reserved.

\section{Introduction}

The phenolic compound is the widely used chemical raw material. Its wastewater is primarily from the coke, petrochemical, resin $t$, insulating material, chemical and plastics plants, perfumery, etc $[1,2,3]$. It exists in the coal tar and various liquefied and gasified products, being one of the mainly used products in the coal processing. With the increase in production scale demand and constant enlargement, phenol becomes one of the key pollutants in the body of water
$[4,5]$. Therefore, the discharged phenolic industrial wastewater has a seriously pollute environment, and now, the phenolic wastewater treatment has become a difficult problem.

Although the phenolic industrial wastewater causes greater hazards to the environment, the phenolic compound is also a chemical raw material in wastewater with extensive application. The purpose of phenolic industrial wastewater treatment is to greatly reduce its phenol content and reduce its pollution to environment as well as to recover the wastewater phenol by applicable technical measure on the premise

\footnotetext{
* Corresponding author.

E-mail address: lu5111284@aliyun.com (S. Lu). 
of satisfying the discharge standard requirements to achieve economy and protect the resource [6,7]. Such phenolic wastewater treatment more confines with the reutilization and recycling treatment principle to a great extent, figuring among the main development directions of the phenolic industrial wastewater treatment technology. However, the manner in which the phenolic substance is recovered shall be based on comprehensive consideration of various technological and economic factors. Researchers of both home and abroad have worked much on the phenolic wastewater treatment and the phenolic substance recovery for many years, having learned different methods such as chemical and biochemical phenol removals $[5,8,9,10]$, but the purpose of a majority of these methods is to oxidize the phenol compound into an innoxious substance such as $\mathrm{CO}_{2}$ and $\mathrm{H}_{2} \mathrm{O}$, thereby making it impossible to recover a large amount of valuable phenol.

W.Kujawski et al. [11]makes a study on the phenolic wastewater treatment in oil refinery by the liquid membrane extraction with various factors influencing on the surveyed phenol removal efficiency and the determined preferred extraction agent formula and process conditionM. Otero et al. [12]adopts the LMS-2-liquid paraffin-kerosene-NaOH liquid membrane system to determine the experimental conditions for the low concentration phenol purification in wastewater and carry out an experiment on the wastewater purification in oil. The results of the experiment show that the method is applicable to a one stage low concentration phenolic wastewater treatment. The technology adopted therein is economical and practical, thus it has an industrial application value.

S. Suresh et al. [13]makes a study on the preferred operating condition for the phenolic wastewater treatment by Lan113B-kerosene- $\mathrm{NaOH}$ liquid membrane system and conducts a two stage high concentration phenolic wastewater treatment with (i.e. above $5 \%$ in concentration). The experiment results show that the phenol removal efficiency is more than 99\%. Bertoncini et al. [14] adopts LMS-2 as a surface active agent, kerosene as a membrane solvent and $\mathrm{NaOH}$ as the inner phase agent to make the liquid membrane system reduce the phenolic wastewater concentration from $1000 \mathrm{mg} /$ $\mathrm{L}$ to $0.5 \mathrm{mg} / \mathrm{L}$. After emulsion breaking, sodium phenolate shall be recovered from the inner phase, and the technology has found its industrial production application yet.

Han et al. [15] adopts Lan-113B (Dialk eny I Succinimide), glycerin, kerosene and the inner phase $\mathrm{NaOH}$ solution to make the liquid membrane system perform the trace phenol separation, enrichment and determination in water. The purpose of this experiment is to make phenol diffuse, migrate and penetrate into the inner phase of the emulsion membrane to immediately have a selective and irreversible reaction with the inner phase $\mathrm{NaOH}$ solution in order to generate sodium phenate (non-permeate) for the achievement of a constant phenol enrichment in water. The common zwitterions do not obstruct phenol enrichment in the process, hence having a high value of consideration in the practical application. Mahajan et al. [16] makes studies the emulsion liquid membrane taking double bivinyl imine-kerosene as the membrane phase. $F$ also considers using a dynamic characteristic in phenol extraction by the emulsion liquid membrane taking $\mathrm{NaOH}$ solution as the inner water phase and determines the influence of the membrane and inner and outer water phases' composition, the stirring speed and the temperature on the extraction rate and obtains extraction rate pattern.

The above mentioned liquid membranes do not adopt the carrier material. Terzyk et al. [17] employs phenol as the study object to introduce the common complex extraction agent TBP for phenol extraction to the liquid membrane as a carrier. The LMS-2 enabling kerosene is taken therein to form the stable membrane phase as a surface active agent and the water-inoil emulsion made of $42.75 \%$ kerosene, $0.25 \%$ TBP, $2 \%$ LMS$2.5 \%$ paraffin. $50 \% \mathrm{NaOH}$ solution is also taken as the liquid membrane extraction agent to extract wastewater with $100 \mathrm{mg} / \mathrm{L}$ phenol concentration from a certain glass fiber reinforced plastic plant whose extraction agent shall have a counter current contact with the membrane extraction agent. The experiment results show that the liquid membrane phenol separation efficiency has greatly improved, with the phenol removal rate being up to $99 \%$.

Shibao Lu et al. [18] adopts DBA, L-113B, liquid paraffin, sulfonated kerosene and inner phase $\mathrm{NaOH}$ solution liquid membrane system to make analyze the phenol migration and enrichment behavior, and determines the preferred condition for the phenol migration and enrichment by the emulsion liquid membrane. The phenol migration rate is up to be more than $99.5 \%$ within $10 \mathrm{~min}$. Under this condition, common coions shall not migrate and penetrate the emulsion liquid membrane. Only phenol shall be favorably separated from the co-ions. The method has been successfully applied to the trace phenol enrichment and determination in water and industrial wastewater, always showing the satisfactory results.

The above mentioned problem can be solved by applying the ionic liquid to inner coupling liquid membrane for the phenol migration. However, there are few reports on the method for phenolic wastewater treatment. Presently, a study on the liquid membrane phenol separation primarily takes the emulsion liquid membrane as the study object since the introduction of a surface active agent to the emulsion liquid membrane system makes the process more complex [19], resulting in contradiction between the emulsion making and breaking processes. The swelling of the liquid membrane dilutes the concentrated solute in the inner phase and reduces the driving force for mass transfer and decreases membrane stability due to the entrainment and osmotic pressure difference.

This paper presents the hydrophobic ionic liquid application to the inner coupling liquid membrane, making a study on the phenol migration pattern and analyzing the influence of factors such as the stirring speed, the experimental temperature, the feed liquid phase acidity and the initial concentration on the migration rate to obtain the preferred condition for migration and provide a theoretic basis for effective phenolic wastewater management.

\section{Experiment}

\section{Reagents and instruments}

Reagents: n-Butyl bromide, N-methylimidazole, ammonium hexafluorophosphate, phenol, and methanol. The reagents 
adopted are analytically pure. The experiment is conducted with the deionized water.

Instruments: The FTIR-8900 type infrared spectrum from Shimizu in Japan, the UV-2102 PC type ultraviolet visible spectrophotometer from Unico (Shanghai) Instrument Co., Ltd, the MAS-1 type atmospheric microwave auxiliary synthesis and/or extraction reaction instrument manufactured by Shanghai Xinyi Microwave Chemical Technology Co., Ltd, and the RE-52A type rotary evaporator from Shanghai Shyarong Biochemical Instrument Plant.

\section{The hydrophobic ionic liquid synthesis}

The synthesis process:

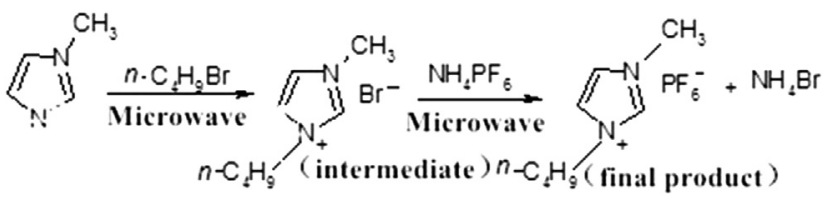

Microwave; intermediate; final product.

(1)Intermediate 1-butyl-3-methylimidazolium bromide [BMIM] $\mathrm{Br}$ preparation

Weigh the raw material with 1.2:1 mol ratio (n-Butyl bromide $\mathrm{N}$-methylimidazole), place it into the reaction flask and then place the flask in the microwave synthesis reaction instrument whose temperature contains $40^{\circ}, 50^{\circ}, 55^{\circ}, 60^{\circ}$ and $85^{\circ}$ properly ordered. The reaction time at every temperature includes $1 \mathrm{~min}, 1 \mathrm{~min}, 1 \mathrm{~min}, 1 \mathrm{~min}$ and $3 \mathrm{~min}$ respectively. The purpose of such progressive heating is to prevent the solution from blasting boiling. After the completion of reaction, employ an acetic ether to clean the product for four times and then carry out a rotary evaporation to place the obtained yellow liquid into the vessel and separate out the yellowish crystal, with $98.08 \%$ yield.

(2)1-butyl-3-methylimidazole hexafluorophosphate [BMIM]PF 6 preparation

Place the generated intermediate and ammonium hexafluorophosphate in a special reaction flask in accordance with 1:1 mol ratio together with moderate deionized water. The microwave synthesis reaction instrument temperature contains $50^{\circ}, 60^{\circ}, 70^{\circ}, 75^{\circ}$ and $85^{\circ}$ properly ordered with the reaction time includeing1 $\mathrm{min}, 1 \mathrm{~min}, 1 \mathrm{~min}, 2 \mathrm{~min}$ and $5 \mathrm{~min}$ respectively. After the completion of reaction, the brown yellow liquid is obtained and shall be subjected to washing for four times and then to a rotary evaporation. Finally, it shall be placed in the vacuum dryer for it to be used later.

\section{[BMIM]PF ${ }_{6}$ used for the inner coupling liquid membrane} phenol migration

Experiment method: the experiment device is as shown in Fig. 1. The feed liquid phase (a) contains $10.0 \mathrm{~mL}$ phenol solution with certain concentration; the stripping phase (b) is $5.0 \mathrm{~mL} \mathrm{NaOH}$ solution with different concentrations and the bottom membrane phase (c) contained in $6.0 \mathrm{~mL}$ of self-

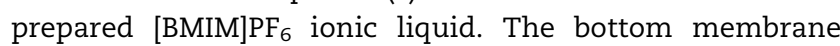

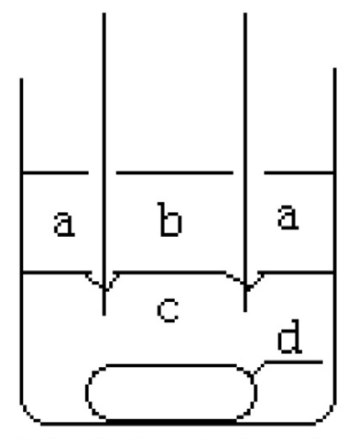

$\mathrm{a}$, the feed liquid phase; $\mathrm{b}$, the stripping phase;

$c$, the membrane phase and $d$ a magnetic stirrer

Fig. 1 - Schematic diagram for experimental device.

employs a magnetic stirrer for stirring. The contact surface between $\mathrm{a}$ and $\mathrm{c}$ is $1.78 \mathrm{~cm}^{2}$ and that between $\mathrm{b}$ and $\mathrm{c}$ is $6.27 \mathrm{~cm}^{2}$. Prior to experiment, the feed liquid and stripping phases are subjected to an ionic liquid equilibrium. Sampling shall be conducted at regular intervals for analysis, the phenol concentration determined by the spectrophotometric method, the migration rate calculated according to the general method, and the membrane phase recycled. Prior to the operation, it shall be subjected to the $2.0 \mathrm{~mol} / \mathrm{L} \mathrm{NaOH}$ solution oscillation equilibrium for $30 \mathrm{~min}$ and then subjected to the deionized water neutralization.

Experiment principle: The phenol migration process by the inner coupling liquid membrane may be due to:

(1) The phenol diffusion to the feed liquid phase with interface occupied by the ionic liquids in the membrane phase. The membrane phase form complex by hydrogen bond binding as shown by the reaction:

$\mathrm{Ph}-\mathrm{OH}+[\mathrm{BMIM}] \mathrm{PF}_{6}=\mathrm{Ph}-\mathrm{OH} \ldots[\mathrm{BMIM}]_{\mathrm{PF}}$

(2) The generated complex diffusion to the membrane phase, with interface occupied by the stripping phase and analytical reaction as shown:

$\mathrm{Ph}-\mathrm{OH} \ldots[\mathrm{BMIM}] \mathrm{PF}_{6}+\mathrm{NaOH}=\mathrm{Ph}-\mathrm{O}^{-}+\left[\mathrm{BMIM}^{-}\right] \mathrm{PF}_{6}+\mathrm{H}_{2} \mathrm{O}$

The stirring action shall offer an opportunity for the metallic ion-carrier complex to fully come into contact with the analytical agent and ensure effective extraction and stripping process to improve the liquid membrane system transmission rate and stability $[20,21,22]$. The analytical liquid with higher metallic ion concentration may be obtained by the volume ratio change between the analytical agent and the liquid membrane solution. Stirring is stopped for standing, the high metallic ion concentration analytical solution and the membrane phase are be subjected to automatically layering, which shall be convenient for the concentration treatment. 
The metallic ion migration in the DSLM is similar with that in the SLM and the process is conducted including the following steps:

(1) Metallic ion $\left(\mathrm{M}_{f}^{2+}\right)$ diffuses from the feed liquid phase and goes through the diffusion layer between the feed liquid and membrane phases.

(2) At the interface between the feed liquid and membrane phases, the metallic ion $\left(\mathrm{M}_{f}^{2+}\right)$ and carrier (HR) undergo a coordination reaction which is as follows:

$\mathrm{M}_{f}^{2+}+\frac{m+n}{2}(\mathrm{HR})_{2, \text { org }} \stackrel{\stackrel{\mathrm{K}_{1}}{\rightleftarrows}}{\rightleftarrows} \mathrm{MR}_{n^{*}} m \mathrm{mR}_{\text {(org) }}+n \mathrm{H}_{f}^{2+}$

where the right subscript org indicates the organic phase, the right subscript $f$ indicates the feed liquid phase and $(H R)_{2}$ indicates the existence form of alkyl phosphonic acid carrier in the non-polar solvent.

(3) The metal-carrier complex generated by the reaction diffuses in the membrane phase.

(4) The metal-carrier complex diffuses to the interface between the membrane and dispersion analytical phases, and undergoes the following analytical reaction with the analytical agent which is as shown below:

$\mathrm{MR}_{n^{*}} m(\mathrm{HR})_{(\mathrm{org})}+n \mathrm{H}_{\delta}^{+} \stackrel{\mathrm{K}_{2}}{\rightleftarrows} \mathrm{M}_{\delta}^{2+}+\frac{m+n}{2}(\mathrm{HR})_{2, \text { org }}$

where the right subscript $\delta$ indicates the analytical phase.

(5) The carrier returns to the interface between the feed liquid and membrane phases.

By supposing that the metallic ion diffusion is linear, concentration of the charged substance entering into the supported liquid membrane with low dielectric constant may be ignored. The chemical reaction at the interface is in a continuous and stable state to derive an osmotic coefficient equation of the metallic ion in the dispersion supported liquid membrane as shown $[23,24,25]$ :

$\frac{1}{P_{c}}=\frac{d_{f}}{D_{f}}+\left(\frac{d_{0}}{D_{0}}+\frac{V_{\delta}}{K_{2} V_{0}}\right) \frac{1}{K_{d}}$

where $P_{c}$ stands for osmotic metallic ion coefficient in the dispersion supported liquid membrane, $K_{d}$ the metallic ion distribution ratio at the interface between the feed liquid and membrane phases, $d_{f}$ the metallic ion's diffusion layer thickness at the interface between the feed liquid and membrane phases, $d_{0}$ the membrane phase thickness, $K_{2}$ the analytical reaction rate constant at the interface between the membrane and dispersion analytical phases, $D_{f}$ the metallic ion diffusion coefficient in the feed liquid phase, $D_{0}$ the metallic ion diffusion coefficient in the liquid membrane phase, $V_{0}$ the membrane phase volume, and $V_{\delta}$ the analytical phase volume respectively.

According to the Equation (1), the metallic ion extraction constant is as follows:
$K_{e x}=\frac{\left[H^{+}\right]^{n}\left[\mathrm{MR}_{n^{*}} m H R\right]}{\left[\mathrm{M}^{2+}\right]\left[(\mathrm{HR})_{2}\right]^{\frac{m+n}{2}}}=\frac{K_{d^{*}}\left[\mathrm{H}^{+}\right]^{n}}{\left[(\mathrm{HR})_{2}\right]^{\frac{m+n}{2}}}$

According to the simultaneous Equations (3) and (4):

$\frac{1}{P_{c}}=\frac{d_{f}}{D_{f}}+\left(\frac{d_{0}}{D_{0}}+\frac{V_{\delta}}{K_{2} V_{0}}\right) \frac{1}{K_{e x}} \frac{\left[H^{+}\right]^{n}}{\left[(H R)_{2}\right]^{\frac{m+n}{2}}}$

Define $\Delta_{f}=\frac{d_{f}}{D_{f}}$ and $\Delta_{0}=\frac{d_{0}}{D_{0}}$. Since the analytical reaction is quick, $\frac{V_{b}}{K_{2} V_{0}}$ may be ignored. Therefore the above mentioned equation may be simplified as follows:

$\frac{1}{P_{c}}=\Delta_{f}+\Delta_{0} \frac{1}{K_{e x}} \frac{\left[H^{+}\right]^{n}}{\left[(H R)_{2}\right]^{\frac{m+n}{2}}}$

It is obvious that, given a certain carrier concentration, the metallic ion diffusion layer thickness $d_{f}$ at the interface between the feed liquid and membrane phases and its diffusion coefficient $D_{0}$ in the liquid membrane may be obtained by the straight slope method.

Next, the metallic ion mass transfer flux may be obtained through the determination of time dependent variation rate $\mathrm{dc} / \mathrm{dt}$ of the metallic ion concentration in the feed liquid phase as follows:

$J=-\frac{V_{f}}{A}\left(\frac{d c_{f}}{d t}\right)=P_{c^{*}} c_{f}$

where $V_{f^{-}}$is the feed liquid phase volume, $A$ the effective membrane area, and $C_{f^{-}}$the concentration of substance migrating in the feed liquid phase.

Integrating Equation (7) we obtain:

$\ln \frac{C_{f(t)}}{C_{f(0)}}=-\frac{A}{V_{f}} P_{c^{*}} t$

where $c_{f(t)}$ and $c_{f(0)}$ are metallic ion concentrations at $t$ and in the initial feed liquid phase respectively. The phenol migration and enrichment are finally completed by the determination of metallic ion concentration given different conditions and plotting a diagram for $-\mathrm{In}\left(\mathrm{c}_{\mathrm{t}} / \mathrm{c}_{0}\right)$ to $\mathrm{t}$ and analyzing the influence of various factors on the migration rate according to the straight slope size $[26,27,28]$.

\section{Results and discussion}

\section{The temperature influence on the migration rate}

The temperature $\mathrm{T}$ influence on the liquid membrane mass transfer is greater. The first reason is that the carrier viscosity decreases with the increase of temperature in the membrane phase, being of great advantage to the transmission of a complex generated by the carrier and the combination of o-nitrophenol and carrier. The second reason is that the increased temperature shall not only increase the o-nitrophenol diffusion rate, but shall also make for the membrane phase generate the complex with an increased analytical speed [29]. 
For the test temperature influence on the o-nitrophenol transmission, the o-nitrophenol transmission speed has been determined under different conditions, and experiment results show the phenol transmission data as shown in Fig. 2. For the migration rate at different temperatures, $-\ln \left(\mathrm{ct} / \mathrm{c}_{0}\right)$ and $t$ show a favorable linear relation within the range of temperature from $300 \mathrm{~K}$ to $320 \mathrm{~K}$ in the experiment, and the slope decreases with the increase of temperature, indicating that phenol migration in the inner coupling liquid membrane undergoes an exothermic reaction. The permeability coefficient $P$ can be obtained at different temperatures according to the slope. The results show that $P$ and temperature show a linear relation, its regression equation is $\mathrm{P}=0.0181-5 \times$ $10-5 \mathrm{~T}(\mathrm{~K})(\mathrm{r}=0.9892)$. The lower temperature shall be more favorable for phenol transmission in order to make it easier to control the experiment with the room temperature $(\mathrm{T}=300 \mathrm{~K})$ selected as reaction temperature accordingly.

\section{The stirring speed influence on the migration rate}

The feed liquid phase $\mathrm{pH}$ is 3.65 , phenol concentration is $10 \mathrm{mg} / \mathrm{L}, 0.1 \mathrm{~mol} / \mathrm{L} \mathrm{NaOH}$ solution in the stripping phase and the relation between $-\ln \left(c_{t} / c_{0}\right)-t$ at different stirring speeds is as shown in Fig. 3. It is observed from the fig that the slope is increases with the increase in the stirring speed, but the experiment shows that when the stirring speed is too high (>400 rpm), the membrane phase is emulsified to a certain extent with a decrease in the mass transfer efficiency. When the speed is $350 \mathrm{rpm}$, the slope is maximum and at this point, $P=3.43 \times 10^{-3} \mathrm{~cm} / \mathrm{s}$. It is advisable to control the stirring speed within the range from 350 to $400 \mathrm{rpm}$ in the experiment to take a control of overpassing the maximum slope required.

The stirring speed on the phenol mass transfer in the supported liquid membrane system is greater, and higher stirring speed shall be more favorable for the mass transfer within certain range [30]. When the stirring speed is within the range from 0 to $300 \mathrm{rpm}$ and as long as it increases, the phenol extraction rate shall increase. When it is more than $300 \mathrm{rpm}$, the phenol extraction rate shows a slow increase, indicating that the boundary layer thickness on both of the membrane sides decreases and down to a minimum with the increase in

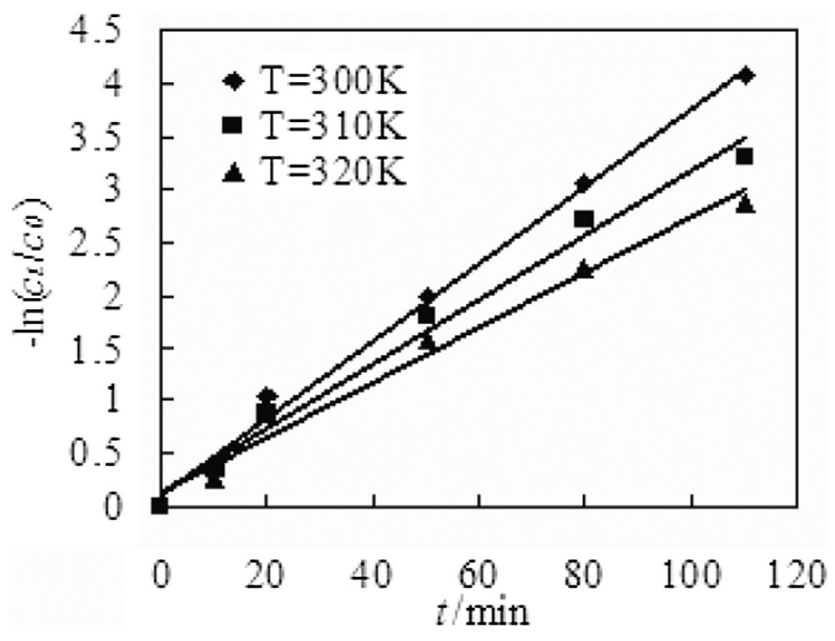

Fig. 2 - Temperature influence on the migration rate.

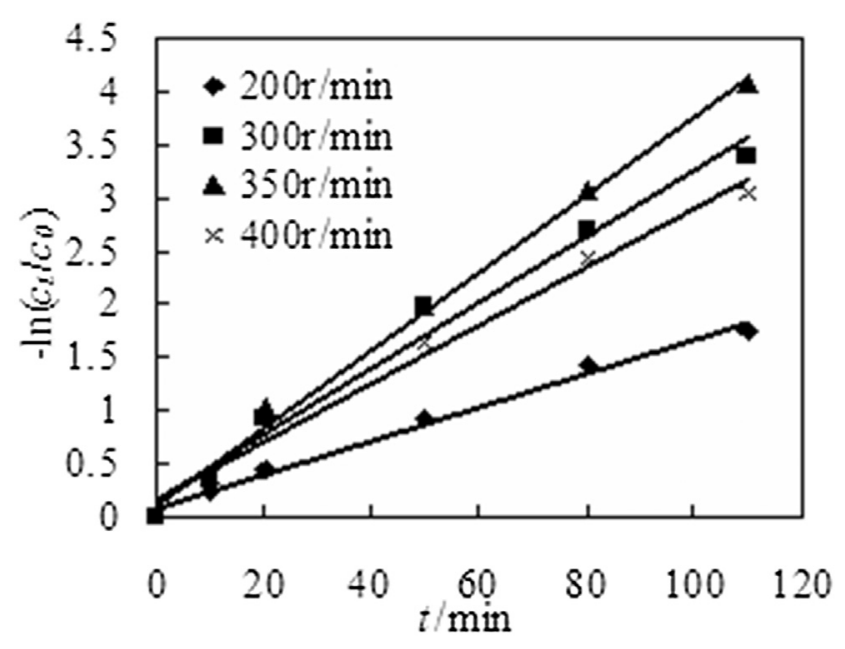

Fig. 3 - The stirring speed influence on the migration rate.

the stirring speed. At this point, it is observed that the variation in resistance to the total mass transfer is not related to the stirring speed. Therefore, a constant increase in stirring speed shall constantly increase the shearing force generated between the solution and the supported liquid membrane and adversely influence the membrane stability and the mass transfer, thus, the stirring speed shall be $410 \mathrm{rpm}$ on both of the supported liquid membrane sides for the experiment.

\section{Different feed liquid phase acidity influence on the migration rate}

It is selected for $10 \mathrm{mg} / \mathrm{L}$ phenol concentration, and $0.1 \mathrm{~mol} / \mathrm{L}$ $\mathrm{NaOH}$ solution in the stripping phase to obtain $-\ln (\mathrm{ct} / \mathrm{c} 0)-\mathrm{t}$ relation as shown in Fig. 4 under different feed liquid phase acidity. It is observed from the figure that when $\mathrm{pH}$ is between 3.65 and 9.18, the slope decrease with the increase in $\mathrm{pH}$ and when $\mathrm{pH}$ is between 3.65 and 6.86, $\mathrm{P}$ and $\mathrm{pH}$ show a linear relation with the regression equation being $\mathrm{P}=5.7 \times 10^{-3}-6 \times 10^{-4} \mathrm{pH}(\mathrm{r}=0.9946)$. The paper selects $\mathrm{pH}$ 3.65 as the preferred acidity for the feed liquid phase since it proves to be more accurate than other acidities.

For the ion transmission process in the supported liquid membrane, the difference in ion concentration is the driving force for the mass transfer between the feed liquid and stripping phases [31,32]. The process has achieved a converse phenol migration and $\mathrm{NaOH}$ ion. The initial concentration of feed liquid is $0.032 \mathrm{~mol} / \mathrm{L}$, the stripping $\mathrm{NaOH}$ concentration is $0.1 \mathrm{~mol} / \mathrm{L}$, and initial carrier concentration is $10 \%$. The initial mass transfer flux is obtained by calculation based on Equation (1) and initial $\mathrm{pH}$ of different feed liquids. When initial feed liquid phase $\mathrm{pH}$ value increases from 3.65 to 6.50 , the initial ion mass transfer flux shall increase too. When $\mathrm{pH}$ is up to 9.18, the increase trend shall decrease to a certain extent. Adopting the above mentioned data process method to obtain the time variable relation of the individual mass transfer coefficient $\mathrm{k}$ in the membrane at initial feed liquid $\mathrm{pH}$ value by calculation. It is observed from Fig. 4 that the individual mass transfer coefficient $\mathrm{k}$ increases in the membrane and then decreases in the mass transfer process. Its variation trend is identical to the 


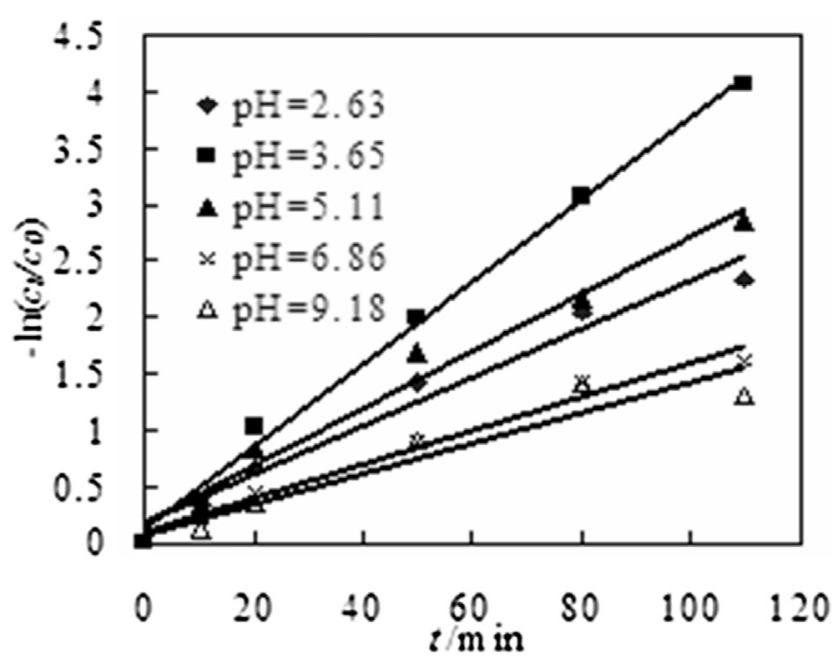

Fig. 4 - The feed liquid phase acidity influence on the migration rate.

individual mass transfer coefficient time variation trend at the initial carrier concentration mentioned above.

The initial concentration influence on the migration rate

Under the feed liquid phase condition for $\mathrm{pH}=3.65$ and the stripping phase $\mathrm{NaOH}$ of $0.1 \mathrm{mo} / \mathrm{L}$, the initial phenol concentration influence has been surveyed in the feed liquid phase. It is observed from Fig. 5 that $-\ln (\mathrm{ct} / \mathrm{c} 0)$ and $t$ show a proper linear relation and that with the increase in phenol concentration, the straight slope decreases, namely the phenol transmission rate will simultaneously decrease. The reason for which the flux of substance through membrane shall be constant by and large is that when membrane area is given, the amount of substance transmitted in unit time is namely a constant to a greater extent. Therefore, the increase in initial phenol concentration is certain to decrease the transmission rate, which confines with experimental result accordingly.

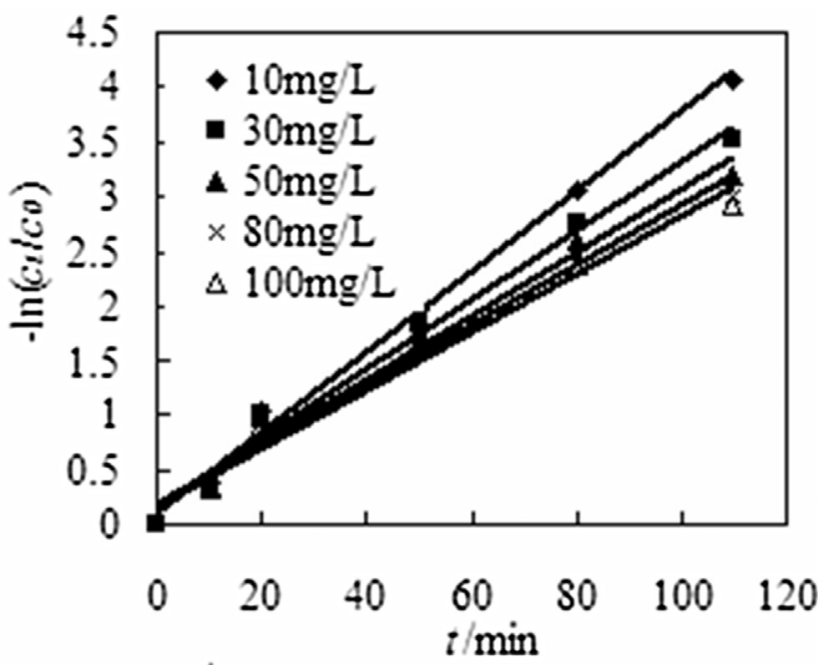

Fig. 5 - The initial concentration influence on the migration rate.
It is observed from the figure that within the concentration range of the surveyed organic phase complexing agent, with the increase in the organic phase complexing agent concentration, the distribution coefficient linearly increases; the reason for which the complex reaction is reversible reaction between phenol and the carrier. The increase in the carrier concentration shall undergo a reversible reaction to move towards the positive direction and the distribution coefficient shall increase [7]. Considering the increase, the distribution coefficient only slightly increase, the reason for which the number of carrier molecules in the organic phase is a lot more than that of phenol in the water phase and that the reaction equilibrium constant in the complex reaction is very large.

\section{$\mathrm{NaOH}$ concentration influence on the migration rate}

Under the condition for $\mathrm{pH}=3.65$ in the feed liquid phase and phenol concentration of $10 \mathrm{mg} / \mathrm{L}, \mathrm{NaOH}$ concentration influence on the phenol transmission has been surveyed in the stripping phase. It is observed from Fig. 6 that $-\ln (\mathrm{ct} / \mathrm{c} 0)$ and $t$ show a favorable linear relation and that the slope increases with the increase in the stripping phase $\mathrm{NaOH}$ concentration, indicating that higher stripping phase alkalinity is more favorable for the phenol migration. However, when $\mathrm{NaOH}$ concentration is more than $0.8 \mathrm{~mol} / \mathrm{L}$, there shall be unapparent increase in slope. Therefore, the paper selects $0.8 \mathrm{~mol} / \mathrm{L}$ as the preferred $\mathrm{NaOH}$ concentration.

With the increase in initial ion concentration in the feed liquid, the initial mass transfer flux increases and the ion concentration also increases at the interface to increase the ion complex concentration at that interface $[33,34]$. When ion concentration increases to certain extent, some generated complex have no time for transmission and result in the increase trend to decrease to another extent. We also observed the flaxen spot as a result of the generated complex failing to be timely transferred to the stripping phase in the experiment. It is observed from the figure that the individual mass transfer coefficient $\mathrm{k}$ increases in the membrane and then decreases in the mass transfer process. Initial feed liquid ion concentration decreases when $\mathrm{k}$ begins to decrease. The shorter time for the

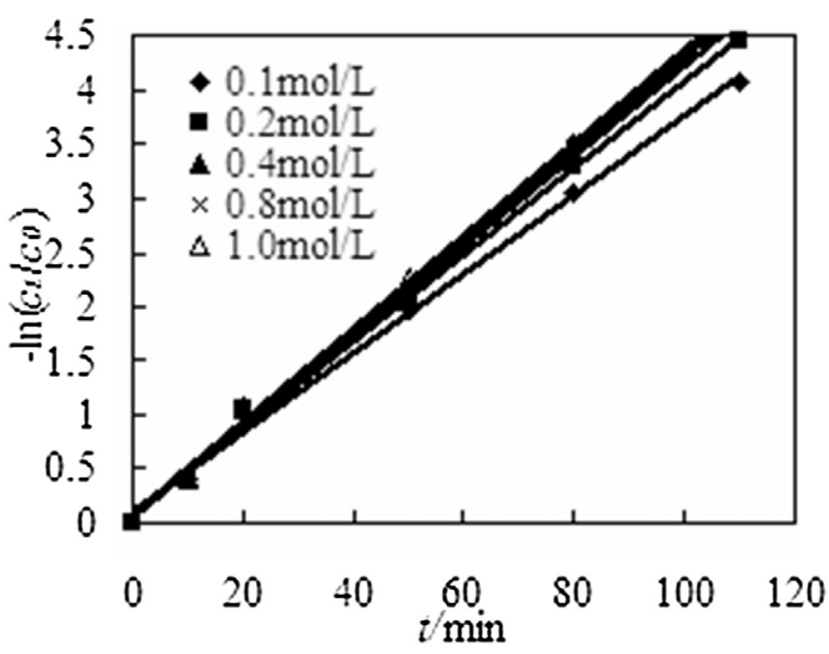

Fig. $6-\mathrm{NaOH}$ concentration influence on the migration rate. 
mass transfer and faster decrease trend of $\mathrm{k}$ shall result in faster membrane liquid loss and unstable supported liquid membrane.

\section{The retention phenomenon}

Under the preferred condition, phenol content has been determined in every phase for different times, the experiment results are shown in Fig. 7. When the migration time $\mathrm{t}=20 \mathrm{~min}$, the sum of phenol concentration in the feed liquid and stripping phases touches the bottom and phenol concentration is up to maximum in the membrane phase. When the migration time $\mathrm{t}=80 \mathrm{~min}$, phenol concentration is approximate to zero in the feed liquid phase, while there is a phenol retained with certain concentration in the membrane phase.

It is observed from experiment that after the phenol migration under the same condition every time, the ion liquid shall be reused after treatment. The results show that with the increase in migration periods, the migration rate shall slightly decrease, and after migration for five times, the migration rate shall still be maintained at more than $95 \%$.

\section{Conclusion}

(1) The experiment on the phenol migration by the inner coupling liquid membrane shows that [BMIM]PF6 liquid membrane system has a significant effect on phenol enrichment and migration. The feed liquid phase acidity, initial concentration and the stripping phase $\mathrm{NaOH}$ concentration influence on the migration rate has been analyzed to obtain the preferred phenol, paranitrophenol and salicylic acid migration condition. It is also observed that there is a retention phenomenon in the membrane phase.

(2) The preferred phenol migration conditions are: the temperature is $300 \mathrm{~K}$, the stirring speed of $350 \mathrm{rpm}$, the

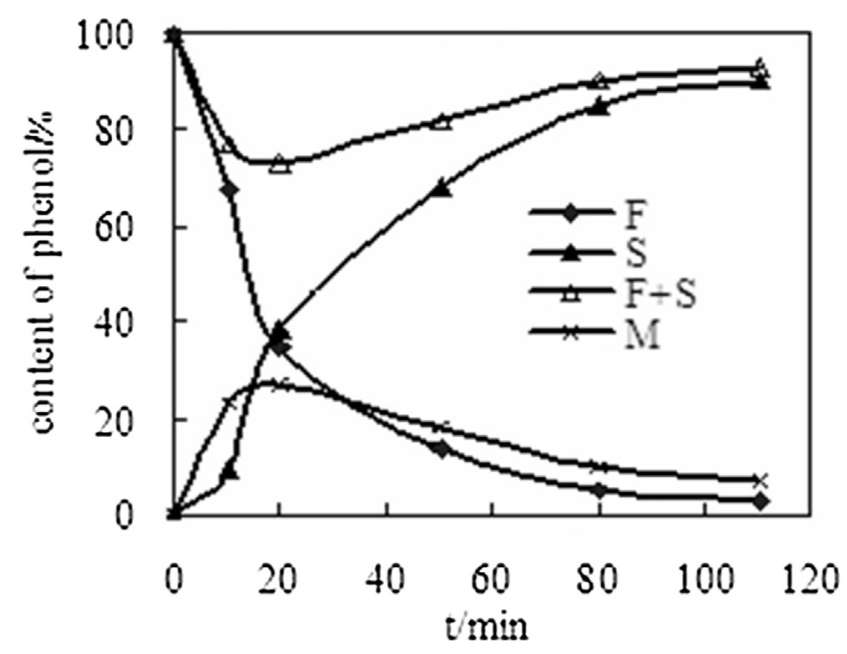

Fig. 7 - The Retention phenomenon. F means the feed liquid phase, $\mathrm{S}$ the stripping phase and $\mathrm{M}$ the membrane phase respectively. feed liquid phase $\mathrm{pH}$ equals to 3.65 , and the stripping phase $\mathrm{NaOH}$ is $0.8 \mathrm{~mol} / \mathrm{L}$, but it is better to employ $\mathrm{NaCI}$ to adjust the ionic strength. Therefore preferred paranitrophenol migration conditions become the following: the feed liquid phase $\mathrm{pH}$ is 3.21 , the stripping phase $\mathrm{NaOH}$ is $0.1 \mathrm{~mol} / \mathrm{L}$ and the ionic strength is 0.4 . Phenol and paranitrophenol can be properly separated in case the feed liquid phase $\mathrm{pH}$ is 9.18 and the preferred salicylic acid migration conditions are: the feed liquid phase $\mathrm{pH}$ is 1.0 , the stripping phase $\mathrm{NaOH}$ is $0.3 \mathrm{~mol} / \mathrm{L}$ and the ionic strength is 0.5 .

(3) There exist the retention phenomena to a certain extent in the migration of the above mentioned substances by the inner coupling liquid membrane system. After migration, the liquid membrane may be recycled after treatment.

\section{Suggestions to further study}

This paper presents hydrophilic ion and hydrophobic ion liquids [BMIM]BF4 and [BMIM]PF6 prepared by the microwave synthesis method, however, it is observed from the experiment results that the microwave synthesis instrument is too high in power, making it difficult to control the reaction and it is prone to blasting boiling. Finally, the prepared ion liquid is adopted in the experiment to directly extract heavy metal copper and lead ions where it is found that there is almost no extraction rate for these two types of ions in such ion liquid. For these problems, following suggestions are made for further study:

(1) The supported liquid membrane material performance and structure have a significant influence on the supported liquid membrane stability and mass transfer rate. There is a liquid membrane loss phenomenon in the experiment mentioned in this paper and a more serious phenol and o-nitrophenol retention in membrane phase, so, such problem shall be subject to the further study.

(2) The ion liquid with better hydrophobicity may be prepared by increasing the side chain length or adopting anion with better hydrophobicity to make a better use of it in the environment taking water for the medium.

(3) The ligating atom or functional group is introduced to the ion liquid substituents such as urea, thiourea and thioether to make the ion liquid directly complex with the metal ion so as to extend application areas of ion liquid and extract or migrate more metallic ions and organics.

\section{Acknowledgment}

The paper is funded by Zhejiang province Funds for Distinguished Young Scientists (Grant No.: LR15E090002) and the 


\section{National Natural Science Foundation of China (Grant No.:51379219)}

\section{R E F E R E N C E S}

[1] Alvarez Gonzalez JR, Macedo EA, Soares ME, Medina AG. Liquid-liquid equilibria for ternary systems of water-phenol and solvents: data and representation with models. Fluid Phase Equilib 1986;26:289-302.

[2] Pinto RTP, Lintomen L, Luz Jr LFL. M.R.Wolf-Maciel, Strategies for recovering phenol from wastewater: thermodynamic evaluation and environmental concerns. Fluid Phase Equilib 2005;228-229:447-57.

[3] Li Z, Wu M, Jiao Z, Bao B, Lu S. Extraction of phenol from wastewater by $\mathrm{N}$-octoyl-pyrrolidine. J Hazard Mater 2004;B114:111-4.

[4] Dabrowski A, Podkoscielny P, Hubicki Z, Barczak M. Adsorption of phenolic compounds by activated carbon-a critical review. Chemosphere 2005;58:1049-70.

[5] Terzyk AP. The impact of carbon surface chemical composition on the adsorption of phenol determined at the real oxic and anoxic conditions. Appl Surf Sci 2007; 253:5752-5.

[6] Stavropoulos GG, Samaras P, Sakellaropoulos GP. Effect of activated carbons modification on porosity, surface structure and phenol adsorption. J Hazard Mater 2008;151:414-21.

[7] Laszlo K, Podkoscielny P, Dabrowski A. Heterogeneity of polymer-based active carbons in the adsorption of aqueous solutions of phenol and 2,3,4-trichlorophenol. Langmuir 2003;19:5287-94.

[8] Efremenko I, Sheintuch M. Predicting solute adsorption on activated carbon:phenol. Langmuir 2006;22:3614-21.

[9] Ania CO, Menendez JA, Parra JB, Pis JJ. Microwave-induced regeneration of activated carbons polluted with phenol. A comparison with conventional thermal regeneration. Carbon 2004;42:1383-7.

[10] Kujawski W, Warzawski A, Ratajczak W, Porebski T, Capala W, Ostrowska I. Removal of phenol from wastewater by different separation techniques. Desalination 2004;163:287-96.

[11] Kujawski W, Warzawski A, Ratajczak W, Porebski T, Capala W, Ostrowska I. Application of pervaporation and adsorption to the phenol removal from wastewater. Sep Purif Technol 2004;40:123-32.

[12] Otero M, Zabkova M, Rodrigues AE. Comparative study of the adsorption of phenol and salicylic acid from aqueous solution onto nonionic polymeric resins. Sep Purif Technol 2005;45:86-95.

[13] Suresh S, Srivastava VC, Mishra IM. Adsorptive removal of phenol from binary aqueous solution with aniline and 4nitrophenol by granular activated carbon. Chem Eng J 2011;171:997-1003.

[14] Bertoncini C, Odetti H, Bottani EJ. Computer simulation of phenol physisorption on graphite. Langmuir 2000;16:7457-63.

[15] Han J, Du Z, Zou W, Li H, Zhang C. In-situ improved phenol adsorption at ions-enrichment interface of porous adsorbent for simultaneous removal of copper ions and phenol. Chem Eng J 2015;262:571-8.

[16] Mahajan OP, Moreno-castilla C, Walker PL. Surface-treated activated carbon for removal of phenol from water. Sep Sci Technol 1980;15:1733-52.

[17] Terzyk AP. Further insights into the role of carbon surface functionalities in the mechanism of phenol adsorption. J Colloid Interface Sci 2003;268:301-29.
[18] Lu Shibao, Pei Liang, Bai Xiao. Study on method of domestic wastewater treatment through new-type multi-layer artificial wetland. Int J Hydrogen Energy 2015;40(34):11207-14.

[19] Banat F, Al-Bashir B, Al-Asheh S, Hayajneh O. Adsorption of phenol by bentonite. Environ Pollut 2000;107:391-8.

[20] Zhou Q Bai H, Xie G, Xiao J. Temperature-controlled ionic liquid dispersive liquid liquid phase microextraction. J Chromatogr 2008;A 1177:43-9.

[21] Mallah MH, Shemirani F, Maragheh MG. Ionic liquids for simultaneous preconcentration of some lanthanoids using dispersive liquid-liquid microextraction technique in uranium dioxide powder. Environ Sci Technol 2009;43:1947-51.

[22] Yousefi SR, Shemirani F. Development of a robust ionic liquid-based dispersive liquid-liquid microextraction against high concentration of salt for preconcentration of trace metals in saline aqueous samples: application to the determination of Pb and Cd. Anal Chim Acta 2010;669:25-31.

[23] Abdolmohammed-Zadeh H, Ebrahimzadeh E. Determination of cobalt in water samples by atomic absorption spectrometry after preconcentration with a simple ionic liquid-based dispersive liquid-liquid microextraction methodology. Cent Eur J Chem 2010;8:617-25.

[24] Yousefi SR, Ahmadi SJ. Development a robust ionic liquidbased dispersive liquid-liquid microextraction against high concentration of salt combined with flame atomic absorption spectrometry using microsample introduction system for preconcentration and determination of cobalt in water and saline samples. Microchim Acta 2011;172:75-82.

[25] Abdolmohammad-Zadeh H, Sadeghi GH. A novel microextraction technique based on 1-hexylpyridinium hexafluorophosphate ionic liquid for the preconcentration of zinc in water and milk samples. Anal Chim Acta 2009;649:211-7.

[26] Khani R, Shemirani F, Majidi B. Combination of dispersive liquid-liquid microextraction and flame atomic absorption spectrometry for preconcentration and determination of copper in water samples. Desalination 2011;266:238-43.

[27] Gharehbaghi M, Shemirani F. Ionic liquid-based dispersive liquid-liquid microextraction and enhanced spectrophotometric determination of molybdenum(VI) in water and plant leaves samples by FO-LADS. Food Chem Toxicol 2011;49:423-8.

[28] Gharehbaghi M, Shemirani F, Baghdadi M. Dispersive liquidliquid microextraction based on ionic liquid and spectrophotometric determination of mercury in water samples. Intern J Environ Anal Chem 2009;89:21-33.

[29] Liu Q-S, Zheng T, Wang P, Jiang J-P, Li N. Adsorption isotherm, kinetic and mechanism studies of some substituted phenols on activated carbon fibers, Chem. Eng J 2010;157:348-56.

[30] Srivastava VC, Swamy MM, Mall ID, Prasad B, Mishra IM. Adsorptive removal of phenol by bagasse fly ash and activated carbon: equilibrium, kinetics and thermodynamics. Colloids Surf A Physicochem Eng Asp 2006;272:89-104.

[31] Yilmaz E, Soylak M. Ionic liquid-linked dual magnetic microextraction of lead(II) from environmental samples prior to its micro-sampling flame atomic absorption spectrometric determination. Talanta 2013;116:882-6.

[32] Anthemidis AN, Ioannou KJG. Sequential injection ionic liquid dispersive liquid-liquid microextraction for thallium preconcentration and determination with flame atomic absorption spectrometry. Anal Bioanal Chem 2012;404:685-91. 
[33] Huang KP, Wang GR, Huang BY, Liu CY. Preparation and application of ionic liquid-coated fused-silica capillary fibers for solid-phase microextraction. Anal. Chim Acta 2009;645:42-7.
[34] Stanisz E, Werner J, Matusiewicz H. Task specific ionic liquidcoated PTFE tube for solid-phase microextraction prior to chemical and photo-induced mercury cold vapor generation. Microchem J 2014;114:229-37. 